Sodi um f I uor i de i nf I uences cal ci um net abol i sm resulting from the suppressi on of ost eocl ast $s$ in the scal es of ni bbl er $\mathrm{fi}$ sh $\mathrm{G}$ rel I a punct at a

\begin{tabular}{|c|c|}
\hline 著者 & $\begin{array}{l}\text { Sat o Nasayuki, Yachi guchi Koj i, Mot ohashi } \\
\text { Kei i chi, Yaguchi Yuki o, Tabuchi Yoshi aki, } \\
\text { K t ani Yoi chi ro, I kari Takahi ro, Ogi so Shouzo, } \\
\text { Seki guchi Toshi o, Hai Tran Ngoc, Huong Do Thi } \\
\text { Thanh, Hoang Nguyen Vi et, Ur at a Nakoto, } \\
\text { M shi ma Hi royuki, Hat or i At suhi ko, Suzuki } \\
\text { Nobuo }\end{array}$ \\
\hline 著者別表示 & $\begin{array}{l}\text { 佐藤 正幸, 木谷 洋一郎, 小木曽 正造, 関口 俊男 } \\
\text {, 浦田 慎, 鈴木 信雄 }\end{array}$ \\
\hline $\begin{array}{l}\mathrm{j} \text { our nal or } \\
\text { publ i cat i on } \mathrm{title}\end{array}$ & Fi sher i es Sci ence \\
\hline vol une & 83 \\
\hline number & 4 \\
\hline page $r$ ange & 543550 \\
\hline year & 2017- 07- 01 \\
\hline URL & ht t p: //doi . or g/10. 24517/00029370 \\
\hline
\end{tabular}




\title{
Aquaculture
}

\section{Sodium fluoride influences calcium metabolism resulting from the suppression of osteoclasts in the scales of nibbler fish}

\section{Girella punctata}

\author{
Masayuki Sato $^{\mathrm{a}}$, Koji Yachiguchi ${ }^{\mathrm{a}}$, Keiichi Motohashi $^{\mathrm{b}}$, Yukio Yaguchi ${ }^{\mathrm{b}}$, Yoshiaki Tabuchi ${ }^{\mathrm{c}}$, \\ Yoichiro Kitani $^{\mathrm{a}}$, Takahiro Ikari ${ }^{\mathrm{a}}$, Shouzo Ogiso ${ }^{\mathrm{a}}$, Toshio Sekiguchi ${ }^{\mathrm{a}}$, Tran Ngoc Hai ${ }^{\mathrm{d}}$, \\ Do Thi Thanh Huong ${ }^{d}$, Nguyen Viet Hoang ${ }^{\mathrm{e}}$, Makoto Urata ${ }^{\mathrm{a}, \mathrm{f}}$, Hiroyuki Mishima ${ }^{\mathrm{g}}$, \\ Atsuhiko Hattori ${ }^{\text {h }}$ and Nobuo Suzuki ${ }^{\mathrm{a}^{*}}$
}

${ }^{a}$ Noto Marine Laboratory, Institute of Nature and Environmental Technology, Kanazawa University, Noto-cho, Ishikawa 927-0553, Japan

${ }^{\mathrm{b}}$ Electron Microscope Center, Tokyo University of Agriculture, Tokyo 156-8502, Japan ${ }^{\mathrm{c}}$ Division of Molecular Genetics Research, Life Science Research Center, University of Toyama, Sugitani, Toyama 930-0194, Japan

${ }^{\mathrm{d} C o l l e g e ~ o f ~ A q u a c u l t u r e ~ a n d ~ F i s h e r i e s, ~ C a n ~ T h o ~ U n i v e r s i t y, ~ C a n ~ T h o ~ C i t y, ~ V i e t n a m ~}$ ${ }^{\mathrm{e}}$ Center of Application and Information, Department of Science and Technology, Camau Province, Vietnam

${ }^{\mathrm{f}}$ Institute of Noto SATOUMI Education Research, Noto-cho, Ishikawa 927-0553, Japan ${ }^{g}$ Department of Medical Hygiene, Kochi Gakuen College, Kochi 780-0955, Japan ${ }^{\mathrm{h}}$ Department of Biology, College of Liberal Arts and Sciences, Tokyo Medical and Dental University, Ichikawa, Chiba 272-0827, Japan

*Correspondence to: Dr. N. Suzuki, Noto Marine Laboratory, Institute of Nature and Environmental Technology, Kanazawa University, Ogi, Noto-cho, Ishikawa 927-0553, Japan. Tel.: 81-768-74-1151; Fax 81-768-74-1644; e-mail: nobuos@staff.kanazawa-u.ac.jp 
ABSTRACT The influence of sodium fluoride (NaF) on calcium metabolism was examined in nibbler fish (marine teleosts). Two days after the administration of $\mathrm{NaF}$ ( $5 \mu \mathrm{g} / \mathrm{g}$ of body weight)(around $10^{-4} \mathrm{M}$ in fish), we showed that plasma calcium levels significantly decreased in NaF-treated nibbler fish. In addition, we detected fluoride in the treated scales by scanning electron microscope with an energy-dispersive X-ray microanalysis, indicating that $\mathrm{NaF}$ directly affects their scales. Therefore, the influence of NaF on osteoblasts and osteoclasts in the scales was examined. In the scales of NaF-injected nibbler fish, tartrate-resistant acid phosphatase (TRAP) (osteoclastic marker enzyme) decreased, although alkaline phosphatase (osteoblastic marker enzyme) was activated. To confirm the effect of $\mathrm{NaF}$ on osteoclasts, furthermore, the mRNA expressions of osteoclastic markers (matrix metalloproteinase- 9 and TRAP) were decreased significantly 2 days after incubation. In barred knifejaws, plasma calcium levels decreased as they did in nibbler fish. Therefore, NaF functions in both osteoblasts and osteoclasts and then influences calcium metabolism in marine fish. In the marine environment, high levels of fluoride (1.2 to $1.5 \mathrm{mg} \mathrm{F}^{-} / \mathrm{l}$ ) (around $10^{-5}$ to $10^{-4} \mathrm{M}$ ) are present in seawater. It is probable that teleosts living in seawater efficiently use fluoride to regulate their blood calcium levels.

Keywords Sodium fluoride · Osteoblasts · Osteoclasts · Scales · Calcium metabolism • Element analysis $\cdot$ Nibbler fish 


\section{Introduction}

Fluoride is widely present in environmental waters and it is generally derived from geological sources [1, 2]. It is also known that fluoride levels in seawater (1.2 to $1.5 \mathrm{mg} \mathrm{F} / \mathrm{l})$ were higher than those in fresh water (0.01 to $0.3 \mathrm{mg} \mathrm{F}^{-} / \mathrm{l}$ ) (see a review [3]). In aquatic animals (particularly marine animals), fluoride tends to accumulate in the exoskeleton of invertebrates and hard tissue, including the bone and scales of fish. For example, krill, which has been used as a feed source for cultured fish, accumulates fluoride in pleon cuticle (2600 ppm/d.w. in Euphausia superba and 3300 ppm/d.w. in Meganyctiphanes norvegica) [4]. Furthermore, dietary fluoride derived from krill exoskeletons accumulates in the vertebral bones of yellowtail [5]. This suggests that fluoride influences bone metabolism in marine teleosts.

Teleost scale is calcified tissue that contains osteoblasts (bone-forming cells), osteoclasts (bone resorption cells), and the bone matrix of two layers [6-11]. Teleost scales play an important role in regulating the blood calcium level because teleost scales are known to function as internal calcium reservoirs, particularly during times of increased calcium demand, such as sexual maturation or starvation [6, 12-14]. Using fish scales, we have developed a fish scale assay system [7, 15]. This fish scale assay has been utilized to analyze hormonal functions $[7,11,15,16]$. Using the scale assay system, we recently indicated that in goldfish Carassius auratus (freshwater teleosts), sodium fluoride (NaF) affects both osteoblasts and osteoclasts [17]. In marine teleosts, however, the direct effect of fluoride on osteoblasts and osteoclasts has not yet been reported.

In the present study, we examined the influence of $\mathrm{NaF}$ on calcium metabolism in a marine teleost species (nibbler fish Girella punctata). To confirm the results in nibbler fish, 
we injected NaF into another marine teleost species (barred knifejaw Oplegnathus fasciatus) and examined the influence of NaF on plasma calcium levels. Furthermore, to investigate the mechanism of $\mathrm{NaF}$ on bone metabolism in marine teleost, we performed both in vivo and in vitro experiments with the scales of nibbler fish.

Thus, we concluded that NaF functions in both osteoblasts and osteoclasts and then influences calcium metabolism in marine teleosts as well as in freshwater teleosts.

\section{Materials and methods}

\section{Animals}

Nibbler fish Girella punctata (both sexes, $n=17,38.5 \pm 1.1 \mathrm{~g}$ ) were captured by fishing in Tsukumo Bay of the Noto Peninsula (Ishikawa Prefecture). After acclimation for approximately 2 weeks, these fish were used in the present experiments. To confirm the results in nibbler fish, barred knifejaws Oplegnathus fasciatus (both sexes, $n=14,124.2 \pm$ 20.4 g) were used, and the effect of $\mathrm{NaF}$ on calcium metabolism was examined. Some of the barred knifejaws were gifts from both Notojima and Uozu aquariums.

All experimental procedures were conducted in accordance with the Guide for the Care and Use of Laboratory Animals of Kanazawa University.

\section{Treatment and blood collection in nibbler fish (in vivo experiment)}

Nibbler fish were anesthetized with $0.04 \%$ of a 2-phenoxyethanol (Wako Pure Chemical Industries, Ltd., Osaka, Japan), and blood samples were then collected from the caudal vessel using a heparinized syringe from individual anesthetized nibbler fish $(n=6)$. Each collected 
sample was put into a $1.5-\mathrm{ml}$ tube. Thereafter, the tube was centrifuged at 15,000 rpm for 3 min. Then, the separated plasma was immediately frozen and kept at $-80{ }^{\circ} \mathrm{C}$ until use. After blood sampling, NaF (purity: 99.0\%, Wako Pure Chemical Industries, Ltd.) (5 $\mu \mathrm{g} / \mathrm{g}$ of body weight) was injected intraperitoneally. The dose of $\mathrm{NaF}$ was determined in accordance with our previous report [17].

Nibbler fish in the control group $(n=6)$ were injected with saline $(0.9 \% \mathrm{NaCl})$ in the same manner as experimental nibbler fish. These nibbler fish were kept in the aquarium for 2 days. These experimental periods were adopted because hormonal and toxicological effects appeared in goldfish in 2 days [16-21]. In addition, our preliminary experiment with nibbler fish indicated that the changes in plasma calcium levels were highest 2 days after injection. During the experimental periods, these nibbler fish were fasted to exclude intestinal calcium uptake from their diet. Two days after injection, blood samples were collected as described above. The separated plasma was immediately frozen and kept at $-80{ }^{\circ} \mathrm{C}$ until use. The total calcium level (mg/100 ml) of the separated plasma was determined using an assay kit (Aquaauto Kainos Calcium Reagent kit, KAINOS Laboratories, Inc., Tokyo, Japan). Calcium in the plasma samples binds to a color coupler (arsenazo III) and forms a blue complex under neutral $\mathrm{pH}$. The depth of the blue color is proportional to the calcium concentration. We measured plasma calcium levels by colorimetry during this color development.

\section{Treatment and blood collection in barred knifejaws (in vivo experiment)}

To confirm the obtained results in nibbler fish, we examined the influence of NaF on plasma calcium levels using NaF-injected barred knifejaws.

These fish were anesthetized with $0.04 \%$ of 2-phenoxyethanol (Wako Pure Chemical Industries, Ltd.). Thereafter, blood sampling was done as described above. NaF (Wako Pure 
Chemical Industries, Ltd.) (5 $\mu \mathrm{g} / \mathrm{g}$ of body weight) was then injected intraperitoneally. Barred knifejaws in the control group were injected with saline $(0.9 \% \mathrm{NaCl})$ in the same manner as experimental fish. These fish were kept in the aquarium for 2 days. Two days after injection, a blood sample was collected from the caudal vessel using a heparinized syringe from individual anesthetized fish. Thereafter, the total plasma calcium level (mg/100 ml) was determined using an Aqua-auto Kainos Calcium Reagent kit (KAINOS Laboratories, Inc.).

\section{Detection of fluoride in the scales of nibbler fish after NaF injection (in vivo experiment)}

To measure the deposition of fluoride in the scales of nibbler fish, epidermal tissues, including scales, from the left side of the anesthetized fish were dissected and lyophilized. Thereafter, scales were taken from the lyophilized tissue and coated with platinum palladium. Samples were observed using a scanning electron microscope (SEM, SU1510, Hitachi HighTechnologies Corporation, Tokyo, Japan) with energy-dispersive X-ray microanalysis (EDS, EX-250X-ac, Horiba Ltd., Kyoto, Japan), as described in Mishima et al. (1995) [22]. SEMEDS analytical conditions were as follows: the accelerating voltage was $15 \mathrm{kV}$, and the measuring time was about 3600 seconds. The quantitative analysis was a standard method. $\mathrm{SiO}_{2}, \mathrm{MgF}_{2}, \mathrm{MgO}, \mathrm{GaP}, \mathrm{MADD}-10$ feldspar (K), and wollastonite (Ca) were used as standard specimens. Using EDS mapping, whole scales of nibbler fish were analyzed. Quantitative analysis of the scale was performed in the range of $400 \mu \mathrm{m} \times 300 \mu \mathrm{m}$. Analysis was performed several times, and F represents the average value of the concentration.

Effects of $\mathrm{NaF}$ on scale osteoblastic and osteoclastic activities (in vivo experiment) 
Before $\mathrm{NaF}$ or saline $(0.9 \% \mathrm{NaCl})$ injection, the scales on the right side were removed under anesthesia with $0.04 \%$ of 2-phenoxyethanol (Wako Pure Chemical Industries, Ltd.). Two days after $\mathrm{NaF}$ or saline injection, scales on the right side were extracted from anesthetized nibbler fish to examine the influences of $\mathrm{NaF}$ on the osteoblasts and osteoclasts with alkaline phosphatase (ALP) and tartrate-resistant acid phosphatase (TRAP) as markers because, in mammals, the effects of hormones and some bioactive substances on osteoblasts and osteoclasts have been investigated using ALP and TRAP as respective markers [23-25]. The mean for ALP or TRAP (8 scales from one fish) was compared with that of the right side (control group).

The methods for measuring ALP and TRAP activities were as follows. An aliquot of 100 $\mu \mathrm{l}$ of an alkaline buffer (100 mM Tris- $\left.\mathrm{HCl}, \mathrm{pH} 9.5 ; 1 \mathrm{mM} \mathrm{MgCl}_{2}\right)$ or an acid buffer $(0.1 \mathrm{M}$ sodium acetate, including $20 \mathrm{mM}$ tartrate, $\mathrm{pH}$ 5.3) was added to each well. Then, each scale was put into its own well in a 96-well microplate. This microplate was immediately frozen at $80{ }^{\circ} \mathrm{C}$ and then kept at $-20^{\circ} \mathrm{C}$ until analysis. An aliquot of $100 \mu \mathrm{l}$ of $20 \mathrm{mM}$ para-nitrophenyl phosphate in an alkaline or acid buffer was then put into each well with the content of the defrosted plate, which had been stored previously at $-20{ }^{\circ} \mathrm{C}$. This plate was incubated at $23{ }^{\circ} \mathrm{C}$ for 60 min while being shaken. After incubation, the reaction was stopped by adding $50 \mu 1$ of $3 \mathrm{~N} \mathrm{NaOH}$. One hundred fifty $\mu 1$ of a reacted solution was transferred to a new plate, and the absorbance was measured at $405 \mathrm{~nm}$. The absorbance was converted into the amount of produced para-nitrophenol (pNP) using a standard curve for pNP.

After measuring both ALP and TRAP activities, the size of each scale was measured with ImageJ. Thereafter, ALP and TRAP activities were normalized to the surface area $\left(\mathrm{mm}^{2}\right)$ of each scale [26]. 


\section{Osteoclastic marker mRNA analysis in NaF-treated nibbler fish scales (in vitro experiment)}

To investigate the effect of $\mathrm{NaF}$ on osteoclasts, osteoclastic marker mRNA expression was measured in addition to marker enzyme activity in vivo. The nibbler fish $(n=5)$ were anesthetized with $0.04 \%$ of 2-phenoxyethanol (Wako Pure Chemical Industries, Ltd.). Then, the scales $(n=8)$ on the right side were collected from anesthetized nibbler fish. To examine changes of genes expressed in osteoclasts that responded to $\mathrm{NaF}\left(10^{-5} \mathrm{M}\right)$, these scales were incubated for 1 and 2 days in Leibovitz's L-15 Medium (Thermo Fisher Scientific Inc., Grand Island, NY, USA) containing a 1\% penicillin-streptomycin mixture (Thermo Fisher Scientific Inc.). This concentration of $\mathrm{NaF}$ was determined in accordance with experiments regarding in vitro cultures (effective doses: $10^{-7}$ to $10^{-4} \mathrm{M}$ ) of osteoblasts in rats [27] and the concentration of sea water (around $10^{-5}$ to $10^{-4} \mathrm{M}$ )[3]. After incubation, the scales were frozen at $-80{ }^{\circ} \mathrm{C}$ for mRNA analysis.

Total RNAs were prepared from nibbler fish scales using a total RNA isolation kit (Isogen, Nippon Gene, Tokyo, Japan). Complementary DNA synthesis was performed using a kit (PrimeScript ${ }^{\mathrm{TM}}$ II 1st strand cDNA Synthesis Kit, Takara Bio Inc., Shiga, Japan). Using the cDNA of control scales, partial fragments of matrix metalloproteinase-9 (MMP-9) were amplified using the degenerate PCR method. The degenerated primer sets for MMP-9 (sense 1: TACCCNTTTGATGGNAARG; antisense 1: GGAGTGATCCAANGGNAG; sense 2: CAGGGNGAYGCNCAYTTTG; antisense 2: TCCAAAYTCRTGNGCNGC) were designed from multiple amino acid sequence alignments of each vertebrate family member. MMP-9 cDNA fragments were amplified by nested PCR (annealing temperature: 
$40{ }^{\circ} \mathrm{C}$ ). The obtained PCR fragments were sequenced. Partial sequences of MMP-9 in nibbler fish were determined.

Gene-specific primers for MMP-9 and TRAP [28] are indicated in Table 1. Elongation factor-1 $\alpha$ (EF-1 $\alpha)$ cDNA was amplified using a primer set [28] (Table 1). The PCR amplification was analyzed using real-time PCR apparatus (Mx3000p, Agilent Technologies, Santa Clara, CA, USA) [16, 29]. In accordance with the manufacturer's protocol, relative quantification was performed by the standard curve method. The stocked cDNA was accurately diluted. We prepared standard curves using the diluted cDNA. The relative quantities determined can be compared across the plates. MMP-9, TRAP, and EF-1 $\alpha$ were annealed at $60{ }^{\circ} \mathrm{C}$. The MMP-9 and TRAP mRNA levels were normalized to the EF-1 $\alpha$ mRNA level.

\section{Statistical analysis}

All results are expressed as the means \pm SE. The statistical significance between the control and experimental groups was assessed using a student's $t$-test or paired $t$-test. In all cases, the selected significance level was $p<0.05$.

\section{Results}

Effects of NaF on the plasma calcium level in nibbler fish and barred knifejaws (in vivo experiment)

The influence of $\mathrm{NaF}$ on calcium metabolism was examined in an in vivo experiment with nibbler fish (marine teleosts). Two days after administration, plasma calcium levels had 
decreased significantly in the NaF-injected nibbler fish, although plasma calcium levels did not change in the control nibbler fish (Fig. 1).

To confirm the results obtained in nibbler fish, we examined the influence of $\mathrm{NaF}$ on plasma calcium levels using NaF-injected barred knifejaws. NaF also induced hypocalcemia in barred knifejaws, although plasma calcium levels did not change in the control barred knifejaws (Fig. 2).

\section{Detection of fluoride in the scales of nibbler fish after NaF injection (in vivo experiment)}

Fluoride was deposited in the scales of nibbler fish using SEM-EDS. We can detect fluoride in the scales of NaF-treated nibbler fish using SEM-EDS. As a result of having measured twice with different scales, the mean value of fluoride in the treated scales (1.57 weight \%) was higher than that in the control scales (0.21 weight \%).

Effects of NaF on osteoblastic and osteoclastic activities in the scales of nibbler fish (in vivo experiment)

We examined the influences of NaF on osteoblasts and osteoclasts with ALP and TRAP as respective markers. As a result, NaF treatment induced the upregulation of ALP activity (Fig. 3a). However, NaF injection significantly decreased TRAP activity (Fig. 3b).

\section{The mRNA expression of osteoclastic markers with NaF treatments (in vitro experiment)}

We partially determined MMP-9 (GenBank accession no. LC198841) sequences in nibbler fish (Fig. 4). Several amino acids were conserved among nibbler fish, medaka, mummichog, and zebrafish. Furthermore, 9 cysteine residues were well conserved in these fish. 
Using the determined sequences, a gene-specific primer was designed (Table 1). MMP-9 mRNA expression in the NaF-treated and control scales was examined. After 1 day of incubation, MMP-9 mRNA expression tended to decrease with NaF treatment (Fig. 5a). Thereafter, the mRNA expression of MMP-9 in the NaF-treated scales decreased significantly as compared with that in control scales after 2 days of incubation (Fig. 5b).

TRAP mRNA expression was downregulated with NaF treatment, as was MMP-9. After 1 day of incubation, TRAP mRNA expression in the NaF-treated scales was slightly lower than that in the control scales (Fig. 5c). After 2 days of incubation, TRAP mRNA expression decreased significantly with NaF treatment, as did the TRAP enzyme (Fig. 5d).

\section{Discussion}

In the present study, we examined the effects of intraperitoneally injected $\mathrm{NaF}(5 \mu \mathrm{g} / \mathrm{g}$ of body weight) in marine teleosts, nibbler fish and barred knifejaws. In the marine environment, fluoride is present in a range from 1.2 to $1.5 \mathrm{mg} \mathrm{F}^{-} / \mathrm{l}$ [3]. Therefore, the dose of fluoride in this study, corresponding to approximately $1.19 \times 10^{-4} \mathrm{M}$ in fish, is close to the environmental fluoride level $\left(0.63 \times 10^{-4}\right.$ to $\left.0.78 \times 10^{-4} \mathrm{M}\right)$ and is not an extreme dose. In the case of krill, fluoride was re-accumulated from environmental seawater at each molt stage because no internal deposition took place [4]. Krill maintain a high fluoride concentration in their cuticle during the molt cycle, indicating that fluoride is a mineral necessary for making cuticle in krill. In the two marine teleost species examined in this study, fluoride induced hypocalcemia. As seawater contains high calcium, fluoride may be involved in the suppression of calcium levels in marine teleosts. Thus, marine organisms may utilize fluoride to regulate minerals. 
Considering that $\mathrm{NaF}$ injection induced osteoblastic marker enzyme activation, it is clear that fluoride has an important role in the regulation of bone metabolism in marine teleosts.

We previously reported that $\mathrm{NaF}$ induces hypercalcemia in goldfish (freshwater teleosts) [17]. We believe that the response to $\mathrm{NaF}$ in marine teleosts is different from that in freshwater teleosts. Receptor activators of nuclear factor-кB (RANK)/receptor activators of nuclear factor- $\kappa \mathrm{B}$ ligand (RANKL)/osteoprotegerin (OPG) signaling may be involved in this phenomenon.

RANK/RANKL/OPG signaling is an important function in osteoclastic activation (see a review, 30). In osteoclasts, RANK binds the ligand (RANKL), resulting in the activation of osteoclasts, whereby multinucleated osteoclasts (an active type of osteoclasts) are induced. In addition, OPG that is a decoy receptor of RANKL inhibits osteoclastogenesis by binding to RANKL. Therefore, the RANKL/OPG ratio has been used as an important indicator of osteoclast activation [31]. Wnt/ $\beta$-catenin signaling promotes new bone formation by upregulating OPG synthesis (see a review, 32). Furthermore, in rat osteoblasts, fluoride activated Wnt/ $\beta$-catenin signaling [27]. In goldfish, we recently reported that OPG mRNA expression did not change significantly between NaF-treated and control scales, although NaF significantly increased RANKL mRNA expression [17]. In goldfish, therefore, the ratio of RANKL/OPG in NaF-treated scales was significantly higher than that in control scales, and then NaF treatment induced the activation of osteoclasts [17]. In the present study, $\mathrm{NaF}$ activated scale osteoblasts but suppressed scale osteoclasts in nibbler fish. We strongly believe that $\mathrm{NaF}$ acts on osteoblasts and then decreases the osteoclastic activity resulting from increased OPG production in nibbler fish. The suppression of osteoclasts with NaF treatment 
was supported by an in vitro experiment for the mRNA expression of osteoclastic markers (MMP-9 and TRAP).

In the present study, we detected fluoride in the scales of nibbler fish. Fluoride can directly interact with the bone mineral matrix. The in vitro fluoridation of bone with fluoride can lead to the conversion of carbonated hydroxyapatite to carbonated fluorapatite, which is more stable and resistant to acid dissolution than is hydroxyapatite (see a review, 33). In the scales of nibbler fish, as well as in the bones and teeth of humans, fluoride may be converted into carbonated fluorapatite, as osteoblasts exist in the scales of nibbler fish [28]. In the control scales, we detected fluoride by using SEM-EDS. In marine teleosts, we believe that the deposition of fluoride occurs under natural conditions. To further understand the function of fluoride on bone metabolism, we will examine the existent form of fluoride that was deposited in the scales.

In the present study, we performed both in vivo and in vitro experiments. Considering both experiments, we concluded that NaF functions in both osteoblasts and osteoclasts and then influences calcium metabolism in marine teleosts. In the marine environment, however, fluoride levels are high (1.2 to $\left.1.5 \mathrm{mg} \mathrm{F}^{-} / \mathrm{l}\right)$ in seawater. Therefore, we believe that teleosts living in seawater efficiently use fluoride to regulate blood calcium levels.

\section{Acknowledgments}

This study was supported in part by grants to N.S. (Grant-in-Aid for Scientific Research [C] No. 16K07871 by JSPS), to A.H. (Grant-in-Aid for Scientific Research [C] No. 24570068 by JSPS), to T.S. (Scientific Research [C] No. 15K07126 by JSPS), and to H.M. (Scientific Research [C] No. 15K11034 by JSPS). This work was performed under the cooperative 
research program of the Institute of Nature and Environmental Technology, Kanazawa University, Acceptance No. 17022, in 2017. We greatly appreciate Notojima and Uozu aquariums for providing us with barred knifejaw.

\section{References}

1. Mandinic Z, Curcic M, Antonijevic B, Carevic M, Mandic J, Djukic-Cosic D, Lekic CP (2010) Fluoride in drinking water and dental fluorosis. Sci Total Environ 408: 3507-3512

2. Gbadebo AM (2012) Groundwater fluoride and dental fluorosis in southwestern Nigeria. Environ Geochem Health 34: 597-604

3. Camargo JA (2003) Fluoride toxicity to aquatic organisms: a review. Chemosphere 50: 251-264

4. Adelung D, Buchholz F, Culik B, Keck A (1987) Fluoride in tissues of krill Euphausia superba Dana and Meganyctiphanes norvegica M. Sars in relation to the moult cycle. Polar Biol 7: 4350

5. Yoshitomi B, Nagano I (2012) Effect of dietary fluoride derived from Antarctic krill (Euphausia superba) meal on growth of yellowtail (Seriola quinqueradiata). Chemosphere 86: 891-897

6. Bereiter-Hahn J, Zylberberg L (1993) Regeneration of teleost fish scale. Comp Biochem Physiol Part A 105: 625-641

7. Suzuki N, Suzuki T, Kurokawa T (2000) Suppression of osteoclastic activities by calcitonin in 
the scales of goldfish (freshwater teleost) and nibbler fish (seawater teleost). Peptides 21: 115124.

8. Yoshikubo H, Suzuki N, Takemura K, Hoso M, Yashima S, Iwamuro S, Takagi Y, Tabata MJ, Hattori A (2005) Osteoblastic activity and estrogenic response in the regenerating scale of goldfish, a good model of osteogenesis. Life Sci 76: 2699-2709

9. Suzuki N, Kitamura K, Nemoto T, Shimizu N, Wada S, Kondo T, Tabata MJ, Sodeyama F, Ijiri K, Hattori A (2007) Effect of vibration on osteoblastic and osteoclastic activities: analysis of bone metabolism using goldfish scale as a model for bone. Adv Space Res 40: 1711-1721

10. Ohira Y, Shimizu M, Ura K, Takagi Y (2007) Scale regeneration and calcification in goldfish Carassius auratus: quantitative and morphological processes. Fisheries Sci 73: 46-54

11. Suzuki N, Somei M, Seki A, Reiter Rj, Hattori A (2008) Novel bromomelatonin derivatives as potentially effective drugs to treat bone diseases. J Pineal Res 45: 229-234

12. Yamada J (1961) Studies on the structure and growth of the scales in the goldfish. Mem Fac Fish Hokkaido Univ 9: 181-226

13. Berg A (1968) Studies on the metabolism of calcium and strontium in freshwater fish I: relative contribution of direct and intestinal absorption. Mem Ist Ital Idrobiol 23: 161-196

14. Mugiya Y, Watabe N (1977) Studies on fish scale formation and resorption II: effect of estradiol on calcium homeostasis and skeletal tissue resorption in the goldfish, Carassius 
auratus, and the killifish, Fundulus heteroclitus. Comp Biochem Physiol Part A 57: 197-202

15. Suzuki N, Hattori A (2002) Melatonin suppresses osteoclastic and osteoblastic activities in the scales of goldfish, J. Pineal Res. 33: 253-258

16. Suzuki N, Danks JA, Maruyama Y, Ikegame M, Sasayama Y, Hattori A, Nakamura M, Tabata MJ, Yamamoto T, Furuya R, Saijoh K, Mishima H, Srivastav AK, Furusawa Y, Kondo T, Tabuchi Y, Takasaki I, Chowdhury VS, Hayakawa K, Martin TJ (2011) Parathyroid hormone 1 (1-34) acts on the scales and involves calcium metabolism in goldfish. Bone 48: 1186-1193

17. Sato M, Hanmoto T, Yachiguchi K, Tabuchi Y, Kondo T, Endo M, Kitani Y, Sekiguchi T, Urata M, Hai TN, Srivastav AK, Mishima H, Hattori A, Suzuki N (2016) Sodium fluoride induces hypercalcemia resulting from the upregulation of both osteoblastic and osteoclastic activities in goldfish, Carassius auratus. Comp Biochem Physiol Part C 189: 54-60

18. Suzuki N, Yamamoto M, Watanabe K, Kambegawa A, Hattori A (2004) Both mercury and cadmium directly influence calcium homeostasis resulting from the suppression of scale bone cells: the scale is a good model for the evaluation of heavy metals in bone metabolism. J Bone Miner Metab 22: 439-446

19. Suzuki N, Yamamoto K, Sasayama Y, Suzuki T, Kurokawa T, Kambegawa A, Srivastav AK, Hayashi S, Kikuyama S (2004) Possible direct induction by estrogen of calcitonin secretion from ultimobranchial cells in the goldfish. Gen Comp Endocrinol 138: 121-127 
20. Omori K, Wada S, Maruyama Y, Hattori A, Kitamura K, Sato Y, Nara M, Funahashi H, Yachiguchi K, Hayakawa K, Endo M, Kusakari R, Yano S, Srivastav AK, Kusui T, Ejiri S, Chen W, Tabuchi Y, Furusawa Y, Kondo T, Sasayama Y, Nishiuchi T, Nakano M, Sakamoto T, Suzuki N (2012) Prostaglandin $E_{2}$ increases both osteoblastic and osteoclastic activities in the scales of goldfish and participates in the calcium metabolism in goldfish. Zool Sci 29: 499-504

21. Yachiguchi K, Matsumoto N, Haga Y, Suzuki M, Matsumura C, Tsurukawa M, Okuno T, Nakano T, Kawabe K, Kitamura K, Toriba A, Hayakawa K, Chowdhury VS, Endo M, Chiba A, Sekiguchi T, Nakano M, Tabuchi Y, Kondo T, Wada S, Mishima H, Hattori A, Suzuki N (2014) Polychlorinated biphenyl (118) activates osteoclasts and induces bone resorption in goldfish. Env Sci Poll Res 21: 6365-6372

22. Mishima H, Sakae T, Kozawa Y (1995) Scanning electron microscopy and energy dispersive spectroscopy analysis of calciotraumatic lines in rat labial dentin after acute exposure to strontium chloride. Scanning Microsc 9: 797-803

23. Vaes G (1988) Cellular biology and biochemical mechanism of bone resorption. Clin Orthop 231: 239-271

24. Dimai HP, Linkhart TA, Linkhart SG, Donahue LR, Beamer WG, Rosen CJ, Farley JR, Baylink DJ (1998) Alkaline phosphatase levels and osteoprogenitor cell numbers suggest bone formation may contribute to peak bone density differences between two inbred strains of mice. Bone 22: 211-216

25. Suda T, Takahashi N, Udagawa N, Jimi E, Gillespie MT, Martin TJ (1999) Modulation of osteoclast differentiation and function by the new members of the tumor necrosis factor receptor and ligand families. Endocr Rev 20: 345-357 
26. Suzuki N, Kitamura K, Omori K, Nemoto T, Satoh Y, Tabata MJ, Ikegame M, Yamamoto T, Ijiri K, Furusawa Y, Kondo T, Takasaki I, Tabuchi Y, Wada S, Shimizu N, Sasayama Y, Endo M, Takeuchi T, Nara M, Somei M, Maruyama Y, Hayakawa K, Shimazu T, Shigeto Y, Yano S, Hattori A (2009). Response of osteoblasts and osteoclasts in regenerating scales to gravity loading. Biol Sci Space 23: 211-217

27. Pan L, Shi X, Liu S, Guo X, Zhao M, Cai R, Sun G (2014) Fluoride promotes osteoblastic differentiation through canonical Wnt/ $\beta$-catenin signaling pathway. Toxicol Lett 225: 3442

28. Yachiguchi K, Sekiguchi T, Nakano M, Hattori A, Yamamoto M, Kitamura K, Maeda M, Tabuchi Y, Kondo T, Kamauchi H, Nakabayashi H, Srivastav AK, Hayakawa K, Sakamoto T, Suzuki N (2014) Effect of inorganic mercury and methylmercury on osteoclasts and osteoblasts in the scales of the marine teleost as a model system of bone. Zool Sci 31: 330-337

29. Thamamongood TA, Furuya R, Fukuba S, Nakamura M, Suzuki N, Hattori A (2012) Expression of osteoblastic and osteoclastic genes during spontaneous regeneration and autotransplantation of goldfish scale: a new tool to study intramembranous bone regeneration. Bone 50: 1240-1249

30. Lacey DL, Boyle WJ, Simonet WS, Kostenuik PJ, Dougall WC, Sullivan JK, Martin JS, Dansey R (2012) Bench to bedside: elucidation of the OPG-RANK-RANKL pathway and the development of denosumab. Nat Rev Drug Discov 11: 401-419

31. Kearns AE, Khosla S, Kostenuik PJ (2008) Receptor activator of nuclear factor $\kappa B$ ligand and osteoprotegerin regulation of bone remodeling in health and disease. Endcr Rev 29: 155-192 
32. Silva I, Branco JC (2011) RANK/RANKL/OPG: literature review. Acta Reumatol Port 36: $209-218$

33. Everett ET (2011) Fluoride's effects on the formation of teeth and bones, and the influence of genetics. J Dent Res 90: 552-560 


\section{Figure legends}

Fig. 1. Effects of NaF on plasma calcium levels $(\mathrm{mg} / 100 \mathrm{ml})$ in nibbler fish (a: control group; b: NaF injected group). $\mathrm{NaF}$ (5 $\mu \mathrm{g} / \mathrm{g}$ of body weight) was injected intraperitoneally after initial blood sampling. Nibbler fish in the control group were injected with saline $(0.9 \% \mathrm{NaCl})$ in the same manner as experimental nibbler fish. Blood sampling was then performed at 2 days. * indicates a statistically significant difference, at $p<0.05$, from the initial values in the control or experimental group. $n=6$ samples; one sample from one fish.

Fig. 2. Effects of NaF on plasma calcium levels $(\mathrm{mg} / 100 \mathrm{ml}$ ) in barred knifejaws (a: control group; b: NaF injected group). NaF (5 $\mu \mathrm{g} / \mathrm{g}$ of body weight) was injected intraperitoneally after initial blood sampling. Barred knifejaws in the control group were injected with saline $(0.9 \% \mathrm{NaCl})$ in the same manner as experimental barred knifejaws. Blood sampling was then performed at 2 days. * indicates a statistically significant difference, at $p<0.05$, from the initial values in the control or experimental group. $n=7$ samples; one sample from one fish.

Fig. 3. Effects of NaF on alkaline phosphatase (ALP) (a) and tartrate-resistant acid phosphatase (TRAP) (b) activities (pNP nmol/ $\mathrm{mm}^{2}$ scale/h) in the scales of nibbler fish 2 days after $\mathrm{NaF}$ injection. Before $\mathrm{NaF}$ or saline $(0.9 \% \mathrm{NaCT})$ injection, the scales on the right side were removed under anesthesia. Two days after NaF or saline injection, the scales on the right side were extracted from anesthetized nibbler fish. Each data indicates the ratio of final value/ initial value. ${ }^{* *}$ and $* * *$ indicate statistically significant differences, at $p<0.01$ and $p<0.001$, respectively, from the values in the control scales. $n=6$ samples; one sample from one fish. 
Fig. 4. Alignment of amino acid sequences of matrix metalloproteinase-9 (MMP-9). Conserved amino acid sequences are indicated by black boxes. The accession numbers are as follows: nibbler fish, LC198841; medaka, NP_001098350.1; mummichog, JAR71850.1; zebrafish, AAI60656.1.

Fig. 5. Expression analysis of osteoclastic markers: matrix metalloproteinase-9 (MMP-9) and tartrate-resistant acid phosphatase (TRAP) mRNAs in scales treated with $\mathrm{NaF}\left(10^{-5} \mathrm{M}\right)$ incubated for 1 and 2 days. a: MMP-9 mRNA expression after 1 day of incubation; b: MMP-9 mRNA expression after 2 days of incubation; c: TRAP mRNA expression after 1 day of incubation; d: TRAP mRNA expression after 2 days of incubation. MMP-9 and TRAP mRNA levels were normalized to the elongation factor-1 $\alpha$ (EF-1 $\alpha)$ mRNA level. The values of the ordinates indicate the relative ratios of MMP-9/ EF-1 $\alpha$ (a and b) and TRAP/ EF-1 $\alpha$ (c and d). * indicates statistically significant differences, at $p<0.05$, from the values in the control scales. $n=5$ samples; one sample from one fish.

\section{Table legend}

Table 1. Primer sequences for real-time quantitative PCR 
(a) Control group (nibbler fish)

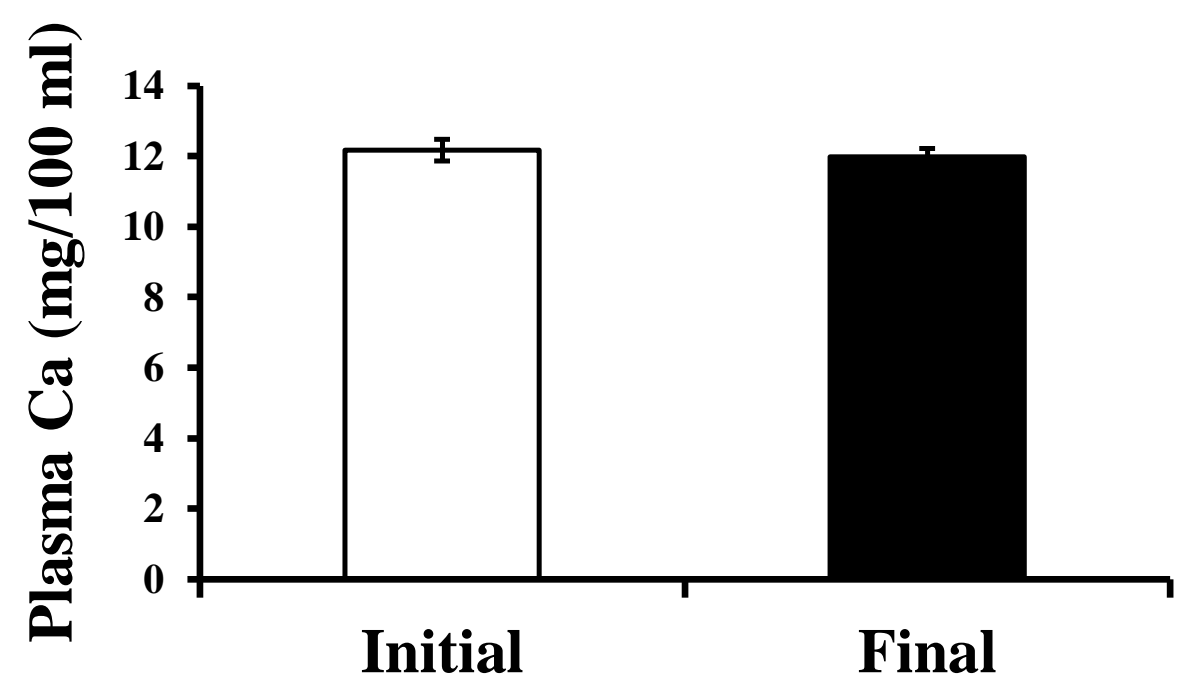

(b) NaF injected group (nibbler fish)

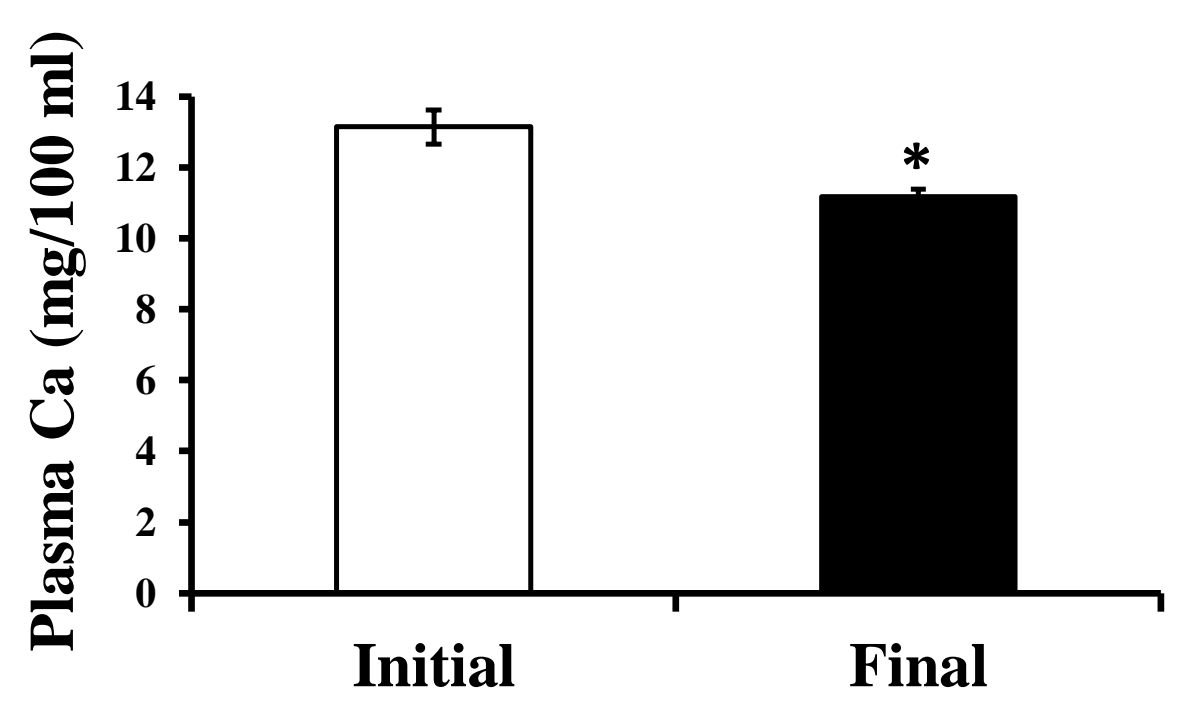


(a) Control group (barred knifejaws)

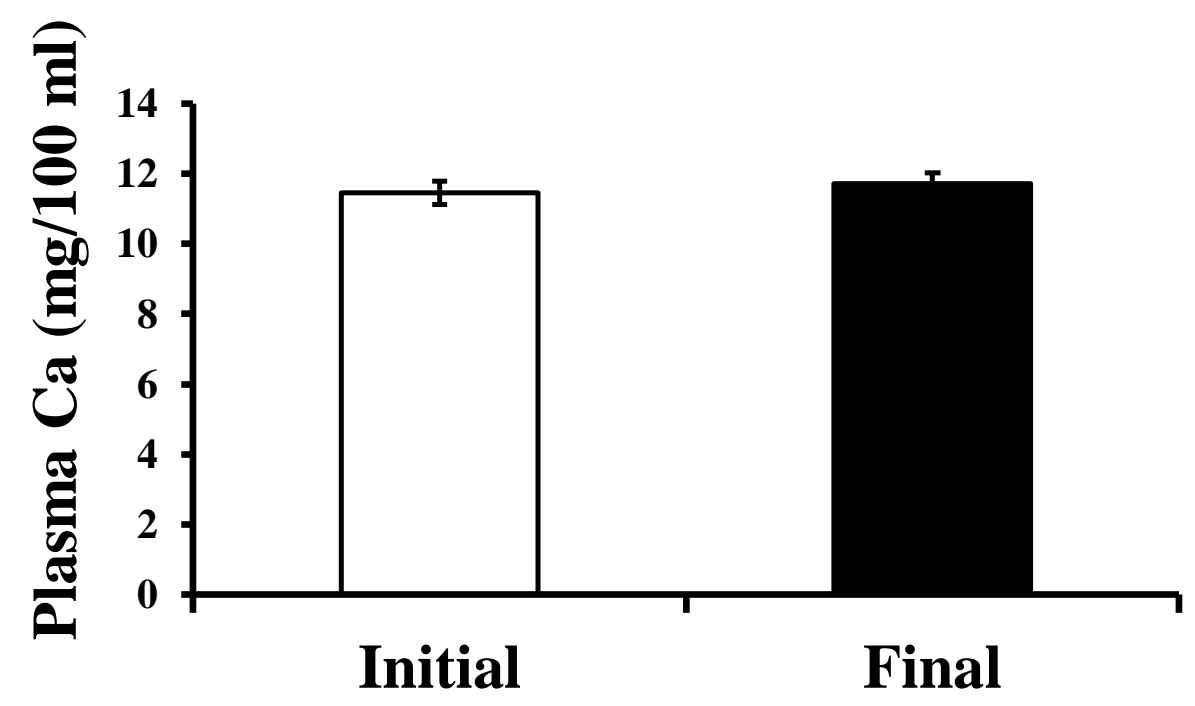

(b) NaF injected group (barred knifejaws)

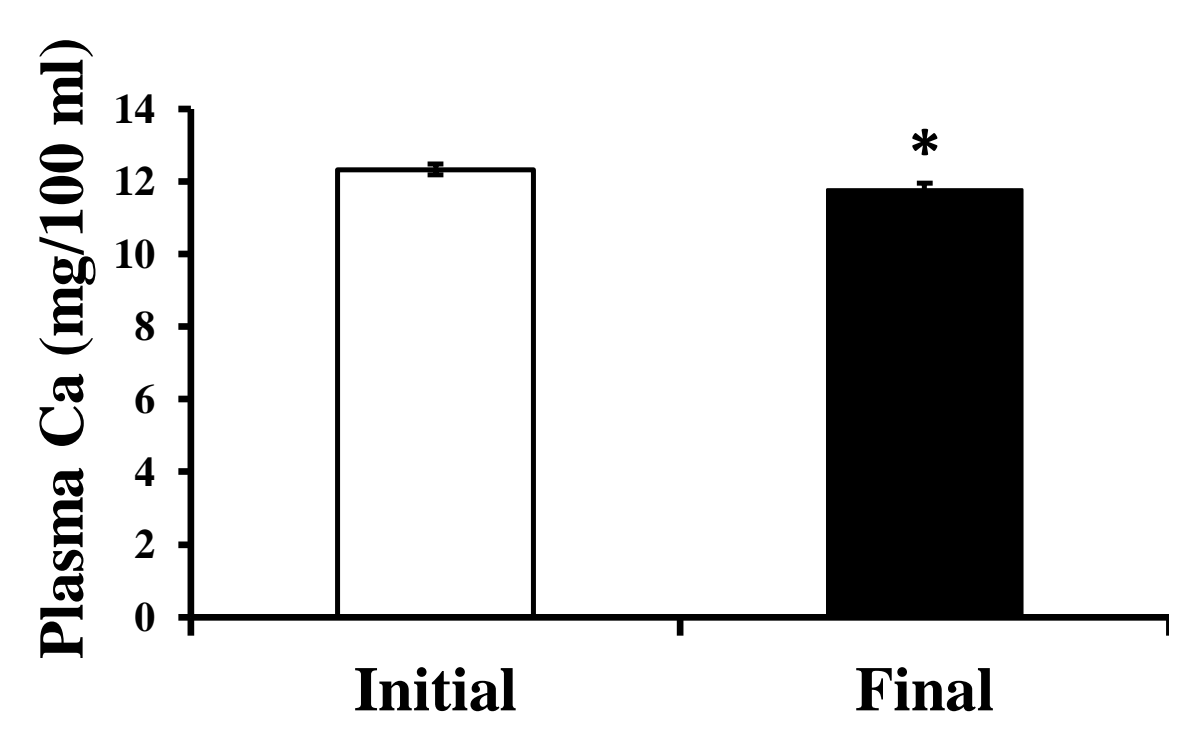


(a) ALP activity

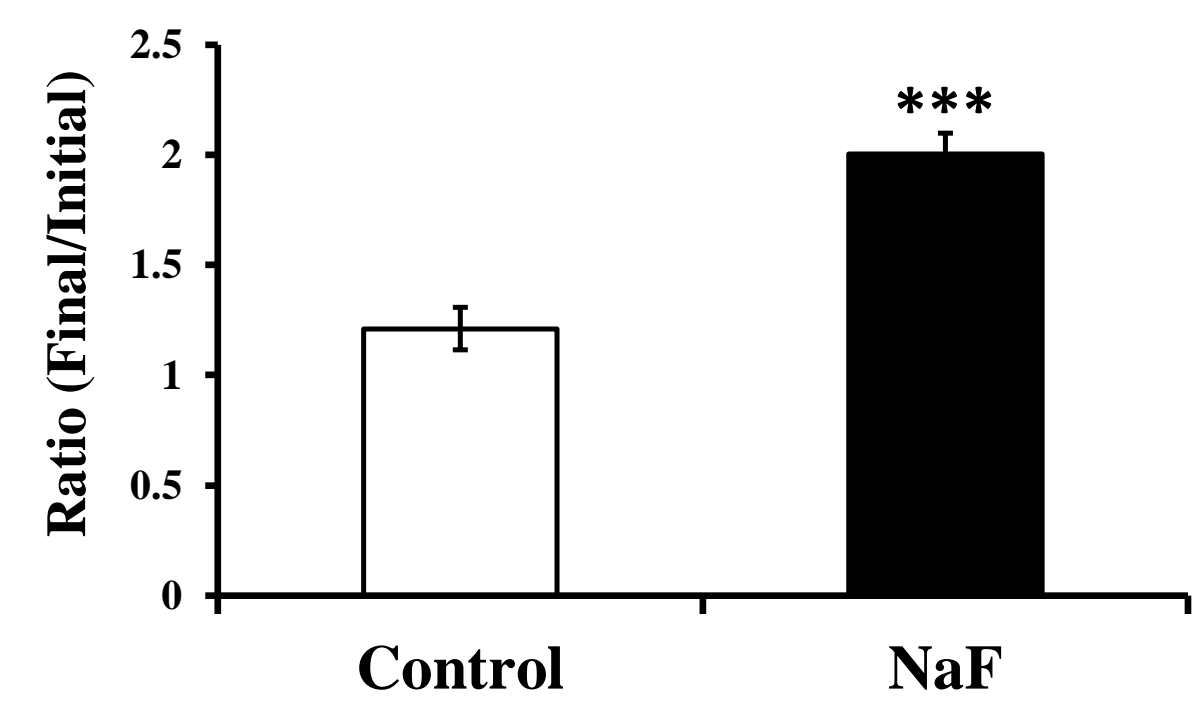

(b) TRAP activity

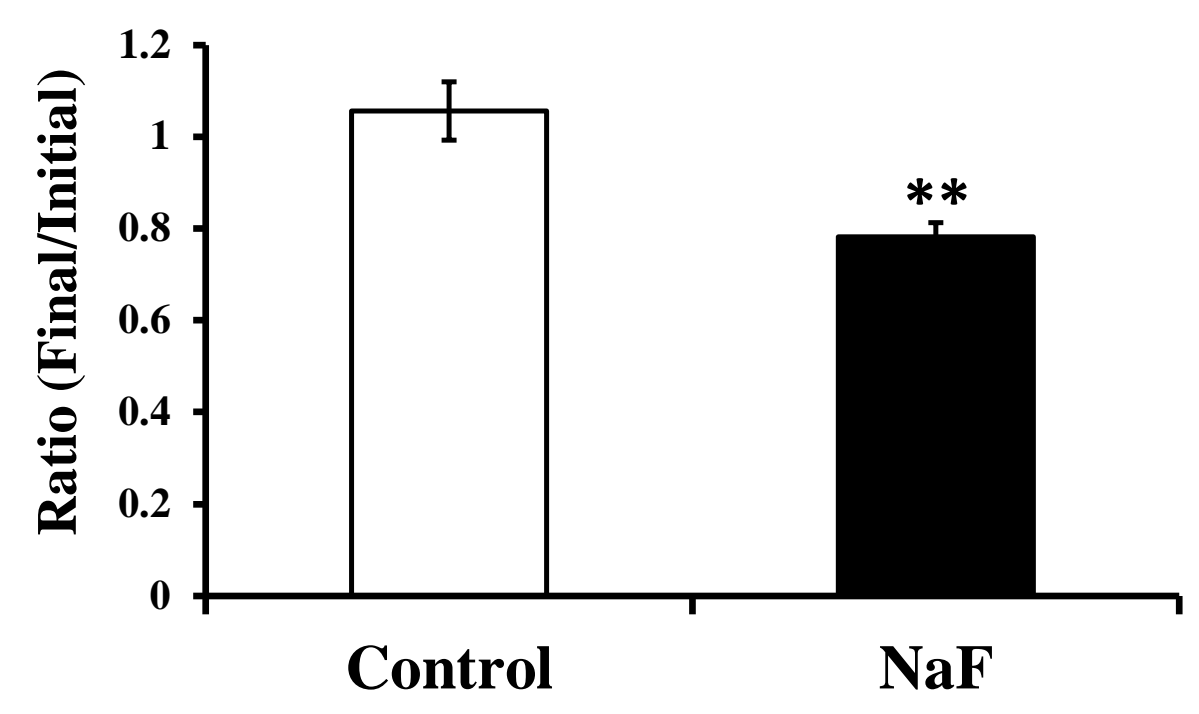


Nibbler fish

Medaka

Mummi chog

Zebrafish

Nibbler fish

Medaka

Mummi chog

Zebrafish

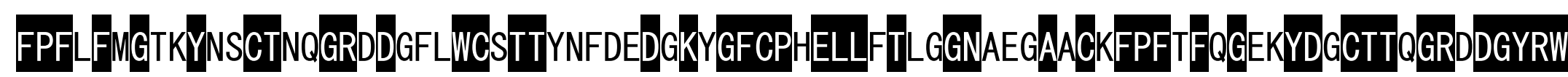
FPFVEGGKTYTSCTSEGRADKLPWCSTTDDYDRDGKY GFCPSELLYTI GGNSDGAKGVFPFVFLGDEYDSCTTEGRRDGYRW FPFTFEGKSYTSCTTEGRTDNLPWCATTEDYGRDKKYYGFCPSELLYTFDGNADGAPGVFPFTFLGKEYDSCTTEGRSDGYRW FPFLFEGTSYSTCTTEGRTDGLPWCSTTADYDKDKKFGFCPSELLFTFDGNSNEAPCVFPFVFDGKKYDSCTTEGRNDGYRW

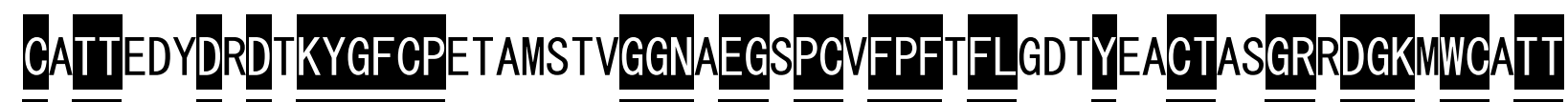

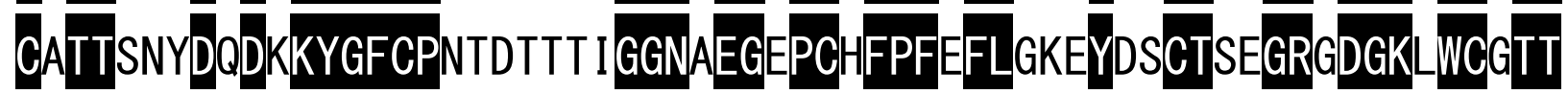

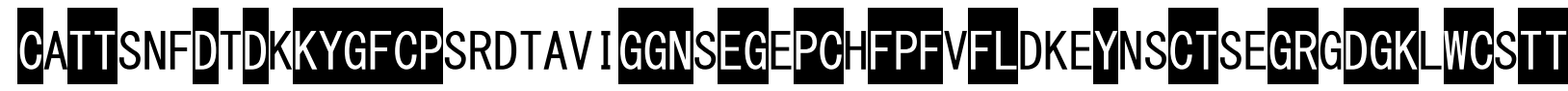

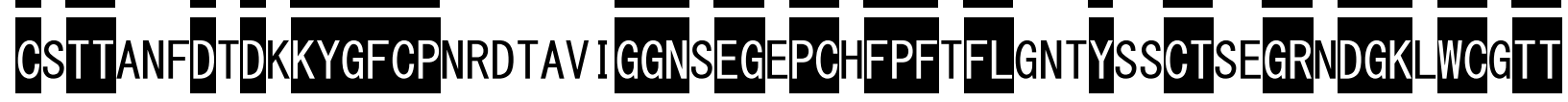


(a) MMP-9, 1 day

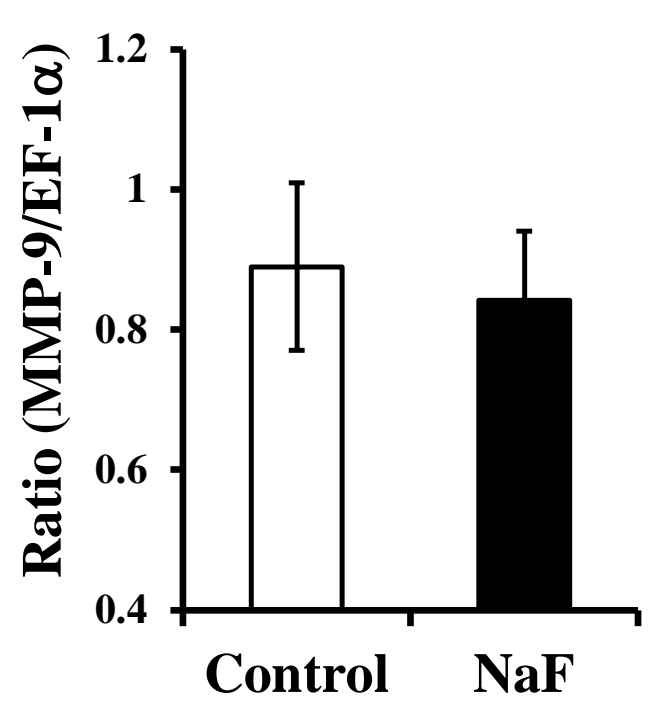

(b) MMP-9, 2 days

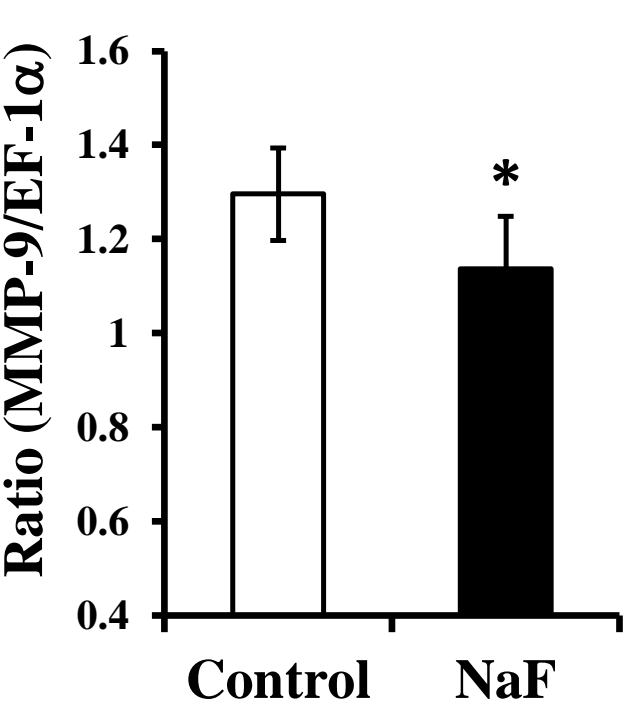

(c) TRAP, 1 day

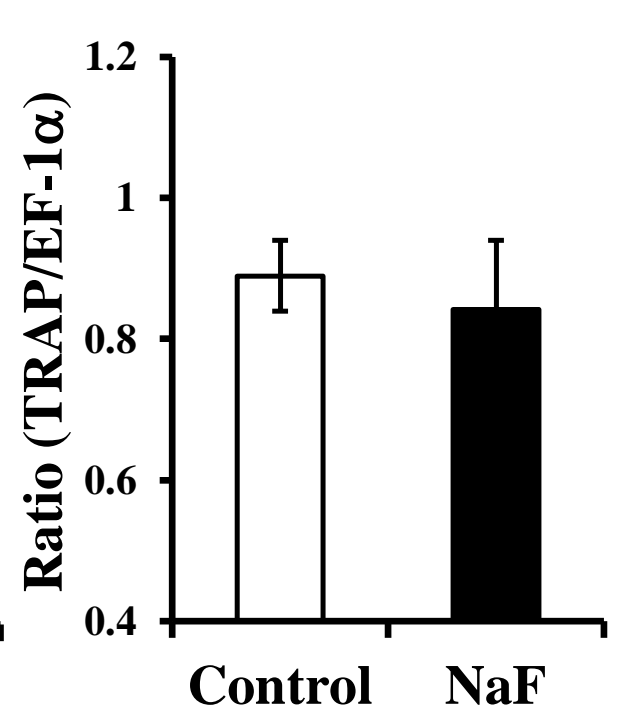

(d) TRAP, 2 days

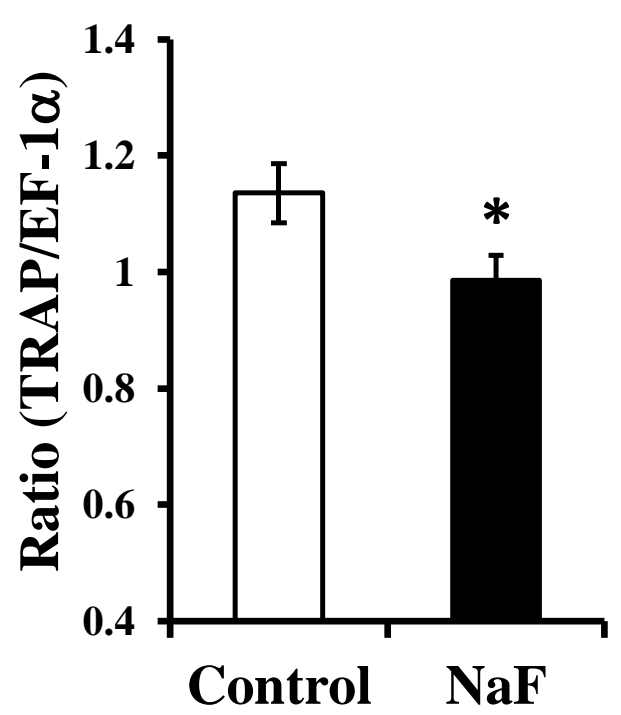


Table 1. Primer sequences for real-time quantitative PCR

\begin{tabular}{lllc}
\hline Name & Forward primer & Reverse primer & Accession number \\
\hline MMP-9 & TGTGGTGCTCAACCACCTACAACT & ATCCCTGCCTTGAGTGGTGCAT & LC198841 \\
TRAP & TGGATGAGAAGCCCAGAGG & CCGCAGAGGTAAGCAGTGG & AB874604 \\
EF-1 $\alpha$ & GTATGGTCGTCACCTTTGCTC & GTGGGTCGTTCTTGCTGTC & AB874605 \\
\hline
\end{tabular}

MMP-9: matrix metalloproteinase-9; TRAP: tartrate-resistant acid phosphatase; EF-1 $\alpha$ : Elongation factor-1 $\alpha$ 